\title{
Defect-related versus excitonic visible light emission from ion beam synthesized Si nanocrystals in $\mathrm{SiO}_{2}$
}

\author{
K. S. Min, ${ }^{a}$ K. V. Shcheglov, C. M. Yang, and Harry A. Atwater \\ Thomas J. Watson Laboratory of Applied Physics, California Institute of Technology, Pasadena, \\ California 91125 \\ M. L. Brongersma and A. Polman \\ FOM Institute for Atomic and Molecular Physics, Kruislaan 407, 1098 SJ Amsterdam, the Netherlands
}

(Received 3 July 1996; accepted for publication 18 July 1996)

\begin{abstract}
Two sources of room temperature visible luminescence are identified from $\mathrm{SiO}_{2}$ films containing ion beam synthesized $\mathrm{Si}$ nanocrystals. From a comparison of luminescence spectra and photoluminescence decay lifetime measurements between $\mathrm{Xe}^{+}$-implanted $\mathrm{SiO}_{2}$ films and $\mathrm{SiO}_{2}$ films containing Si nanocrystals, a luminescence feature attributable to defects in the $\mathrm{SiO}_{2}$ matrix is unambiguously identified. Hydrogen passivation of the films selectively quenches the matrix defect luminescence, after which luminescence attributable to Si nanocrystals is evident, with a lifetime on the order of milliseconds. The peak energy of the remaining luminescence attributable to Si nanocrystals "redshifts" as a function of different processing parameters that might lead to increased nanocrystal size and the intensity is directly correlated to the formation of Si nanocrystals. Upon further annealing hydrogen-passivated samples at low temperatures $\left(<500{ }^{\circ} \mathrm{C}\right)$, the intensity of nanocrystal luminescence increases by more than a factor of 10. (C) 1996 American Institute of Physics. [S0003-6951(96)01940-7]
\end{abstract}

Visible light emission from low-dimensional group IV materials has received worldwide attention over the past few years, due to scientific and technological interest in development of silicon-based light emitters that could be monolithically integrated with advanced silicon microelectronics. ${ }^{1}$ Since the discovery of porous $\mathrm{Si}^{2}$ many techniques have been developed to synthesize light emitting group IV nanocrystals. ${ }^{3-8}$ Ion beam synthesis of group IV nanocrystals in thermal $\mathrm{SiO}_{2}$ offers several technologically important advantages, including integrated circuit process compatibility and significant control over the nanocrystal size distribution, as well as chemical and mechanical stability. Although ion beam synthesis has been widely reported ${ }^{6-8}$ the origin of visible luminescence from ion beam synthesized $\mathrm{Si}$ nanocrystals has so far been unclear, primarily due to a lack of distinction between luminescence originating from matrix defects and luminescence originating from nanocrystals. It is well known ${ }^{9-11}$ that defects in $\mathrm{SiO}_{2}$ display luminescence at various energies including the visible range, so the interpretation of luminescence spectra without distinction of the contribution from defects can be very misleading.

In this letter, we provide experimental results on $\mathrm{Si}$ nanocrystals in $\mathrm{SiO}_{2}$ made by ion implantation that clearly distinguishes visible photoluminescence (PL) originating from the nanocrystals from that which originates from matrix defects. From a comparison of PL spectra and lifetime measurements between $\mathrm{Xe}^{+}$-implanted $\mathrm{SiO}_{2}$ and $\mathrm{SiO}_{2}$ films containing nanocrystals, a luminescence feature is clearly identified as arising from irradiation-damaged $\mathrm{SiO}_{2}$. We demonstrate that subsequent hydrogen passivation of the films containing nanocrystals completely quenches the defect-related luminescence. The remaining PL band attributable to Si nanocrystals displays "redshifts" in peak energy

${ }^{a)}$ Electronic mail: ksmin@daedalus.caltech.edu as a function of processing parameters that might lead to increases in nanocrystal size, and the measured lifetimes are on the order of milliseconds. Upon further annealing hydrogen passivated samples at low temperatures, the intensity of the PL band originating from Si nanocrystals increases by as much as a factor of 10 .

Wet thermal $\mathrm{SiO}_{2}$ films, $100 \mathrm{~nm}$ thick, grown on lightly $p$-doped (100) Si wafers were implanted at room temperature with $50 \mathrm{keV}{ }^{28} \mathrm{Si}^{+}$at doses of $1 \times 10^{16} / \mathrm{cm}^{2}, 2 \times 10^{16} / \mathrm{cm}^{2}$, and $5 \times 10^{16} / \mathrm{cm}^{2}$, corresponding to peak excess Si concentrations of 2,4 , and 10 at. $\% \mathrm{Si}$, respectively, as calculated using the TRIM code. ${ }^{12}$ The samples were subsequently annealed in high vacuum at temperatures ranging between 400 and $1200{ }^{\circ} \mathrm{C}$ for a fixed time of $10 \mathrm{~min}$ or for times ranging between 10 and $320 \mathrm{~min}$ at a fixed temperature of $1000^{\circ} \mathrm{C}$. For selected samples, the presence of $\mathrm{Si}$ nanocrystals was verified by transmission electron microscopy. Si $2 p$ core level x-ray photoelectron spectroscopy (XPS) was performed using a monochromated $\mathrm{Al} K \alpha$ radiation at $1487 \mathrm{eV}$. A pure Gaussian deconvolution of the (100) Si $2 p_{3 / 2}$ signal revealed a full width at half maximum $\Delta E_{\mathrm{FWHM}}=0.72 \mathrm{eV}$. All XPS spectra were corrected for any charging effects by fixing the adventitious $\mathrm{C}(1 \mathrm{~s})$ binding energy at $285 \mathrm{eV}$. For transmission electron microscopy (TEM) and XPS studies, all samples were thinned using HF so that the analyzed cross section lies at the peak of the implantation distribution. Hydrogen passivation experiments were performed by means of low energy $(600 \mathrm{eV})$ deuterium implantation using a Kauffman ion source and the $\mathrm{D}$ dose was determined by elastic recoil spectrometry using a $2.0 \mathrm{MeV}{ }^{4} \mathrm{He}^{++}$beam. (Deuterium was chosen instead of hydrogen in order to facilitate concentration determination.) All photoluminescence spectra were taken with $50 \mathrm{~mW} / \mathrm{mm}^{2}$ excitation using $457.9 \mathrm{~nm}$ $\mathrm{Ar}^{+}$laser radiation, detected using a grating spectrometer and the thermoelectrically cooled $256 \times 1024 \mathrm{Si}$ CCD array 


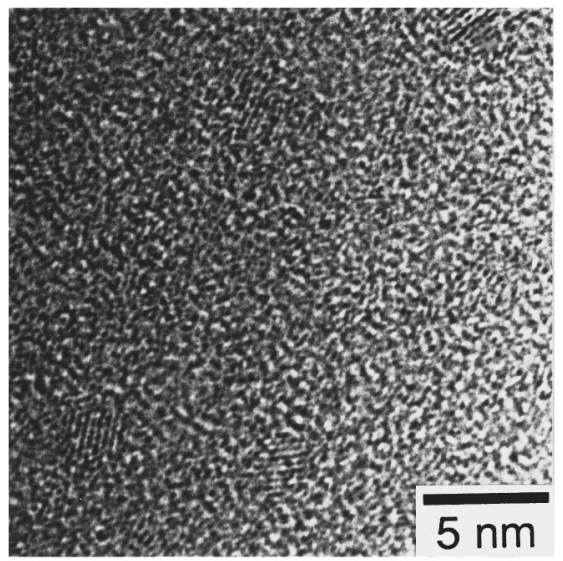

FIG. 1. High resolution TEM image of $\mathrm{Si}$ nanocrystals in $\mathrm{SiO}_{2}$ synthesized from thermal $\mathrm{SiO}_{2}$ implanted with $50 \mathrm{keV} \mathrm{Si}{ }^{+}$to a dose of $5 \times 10^{16} / \mathrm{cm}^{2}$. Precipitation was carried out by annealing in vacuum at $1000{ }^{\circ} \mathrm{C}$ for $40 \mathrm{~min}$.

detector. All spectra have been corrected for system response. Samples for all PL lifetime measurements were cooled to $15 \mathrm{~K}$ using a closed-cycle He cryostat and pumped to a steady state with $475 \mathrm{~nm} \mathrm{Ar}^{+}$laser radiation ( $1 \mathrm{~mW} / \mathrm{mm}^{2}$ ) prior to measurements. Lifetime traces were taken using a GaAs photomultiplier tube in combination with a multichannel photon counter. The time resolution of the experimental setup was $100 \mathrm{~ns}$.

Figure 1 shows a plan-view high resolution TEM image of a $\mathrm{SiO}_{2}$ film implanted with $5 \times 10^{16} / \mathrm{cm}^{2} \mathrm{Si}$ at $50 \mathrm{keV}$ and annealed at $1000{ }^{\circ} \mathrm{C}$ for $40 \mathrm{~min}$. Despite weak contrast, a dense array of $\mathrm{Si}$ nanocrystals is visible, with sizes ranging from 1 to $3 \mathrm{~nm}$ in diameter. It should be noted that due to low contrast between small $\mathrm{Si}$ nanocrystals and the amorphous $\mathrm{SiO}_{2}$ background, quantitative information on size distribution of particles obtainable from TEM is limited and TEM analysis alone could lead to an underestimation of the particle density of small nanocrystals less than about $1.5 \mathrm{~nm}$.

Additional information about nanocrystal formation was obtained using XPS. Figure 2 shows the Si $2 p$ core level spectra of $\mathrm{SiO}_{2}$ films implanted with $5 \times 10^{16} / \mathrm{cm}^{2} \mathrm{Si}$ and annealed at temperatures between 400 and $1100{ }^{\circ} \mathrm{C}$ for 10 min. For comparison, spectra of hydrogen terminated (100) $\mathrm{Si}$ and the unimplanted substrate $\left(100 \mathrm{~nm}\right.$ wet thermal $\mathrm{SiO}_{2}$ on $100 \mathrm{Si}$ ) are also shown. Several trends are noteworthy in Fig. 2. First of all, the Si $2 p$ core level of the as-implanted oxide film is shifted and inhomogeneously broadened towards lower binding energy relative to the unimplanted oxide, characteristic of a suboxide with contributions from various $\mathrm{Si}^{x+}$ oxidation states. ${ }^{13}$ The phase separation of the suboxide into $\mathrm{Si}$ and $\mathrm{SiO}_{2}$ occurs gradually with increasing annealing temperature, as can be deduced from the gradual shifting of the suboxide peak towards the stoichiometric $\mathrm{SiO}_{2}$ binding energy and a distinct bulk $\mathrm{Si}$ peak appearing for samples annealed at temperatures higher than $600{ }^{\circ} \mathrm{C}$. It is noteworthy that the presence of small nanocrystals for samples annealed at 800 and $600{ }^{\circ} \mathrm{C}$ can be inferred from the XPS spectra, although we could not observe them by transmission electron microscopy.

From the XPS spectra of Fig. 2, we can also obtain valuable information about the annealing kinetics of $\mathrm{SiO}_{2}$, whose

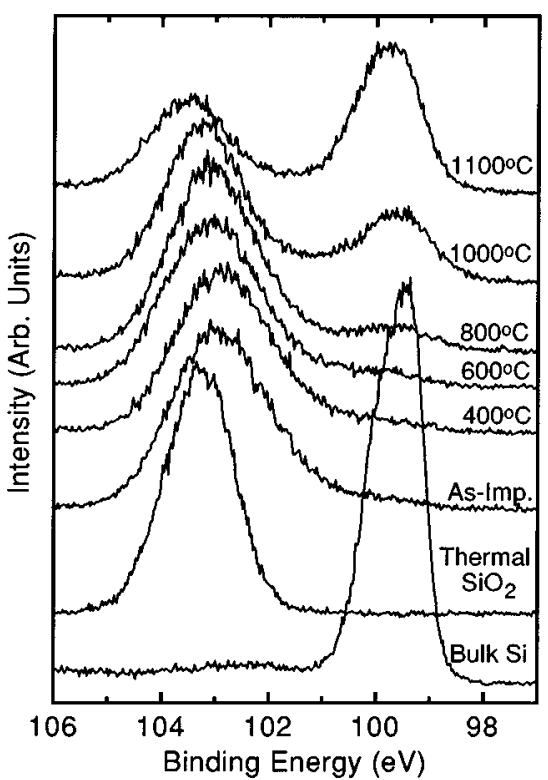

FIG. 2. XPS spectra of $50 \mathrm{keV} \mathrm{Si}^{+}$-implanted $\mathrm{SiO}_{2}\left(5 \times 10^{16} / \mathrm{cm}^{2} \mathrm{Si}\right)$ annealed at various temperatures. As a comparison, XPS spectra of unimplanted $100 \mathrm{~nm} \mathrm{SiO}_{2}$ on $\mathrm{Si}$ and hydrogen terminated (100) bulk Si are also shown.

properties are known to be significantly altered during the process of ion implantation. ${ }^{14}$ This is important for two reasons. First, suboxides leading to imperfect nanocrystal/ $/ \mathrm{SiO}_{2}$ interfaces could give rise to channels for nonradiative recombination of quantum-confined excitons. Second, it was previously demonstrated ${ }^{11}$ from $\mathrm{Xe}^{+}$-irradiated $\mathrm{SiO}_{2}$ that some defects created during the implantation process display visible luminescence upon annealing at $800{ }^{\circ} \mathrm{C}$. The analysis of Fig. 2 reveals that the peak of Si $2 p$ core level of the damaged matrix approaches the value for stoichiometric $\mathrm{SiO}_{2}$ only upon annealing at temperatures as high as $1100^{\circ} \mathrm{C}$. The full width at half-maximum, however, remains approximately $0.3 \mathrm{eV}$ larger than that of the unimplanted film even after annealing at $1100{ }^{\circ} \mathrm{C}$. We can, therefore, expect the presence of optically active defects in the damaged matrix even after high temperature annealing.

Figure 3(a) shows the PL spectra of the $\mathrm{SiO}_{2}$ film implanted with $120 \mathrm{keV} \mathrm{Xe}+$ to a dose of $3 \times 10^{16} / \mathrm{cm}^{2}$ and annealed at $1000{ }^{\circ} \mathrm{C}$ for $10 \mathrm{~min}$. Upon annealing, the defectrelated visible PL becomes intense, marked by a broad peak around $600 \mathrm{~nm}(2.07 \mathrm{eV})$ and a lifetime less than $100 \mathrm{~ns}$ at $550 \mathrm{~nm}$ (i.e., shorter than the experimental resolution of 100 ns). Figure 3(a) also illustrates that this defect-related visible PL can be completely quenched with about $3.3 \times 10^{15} / \mathrm{cm}^{2}$ deuterium. Figure 3(b) illustrates the same set of experiments on $\mathrm{SiO}_{2}$ films implanted with $50 \mathrm{keV} \mathrm{Si}^{+}$. In addition to the defect-related PL band, the PL spectra of $\mathrm{Si}^{+}$-implanted $\mathrm{SiO}_{2}$ are characterized by the emergence of another PL band around $790 \mathrm{~nm}(1.57 \mathrm{eV})$ upon annealing at $1100{ }^{\circ} \mathrm{C}$ in vacuum for $10 \mathrm{~min}$. While deuterium passivation leads to a complete suppression of the defect-related PL band around $600 \mathrm{~nm}$, the intensity of the "red" PL band around $790 \mathrm{~nm}$ does not decrease further upon increasing the deuterium dose beyond $3.3 \times 10^{16} / \mathrm{cm}^{2}$.

Several trends suggest that the origin of the "red" lumi- 


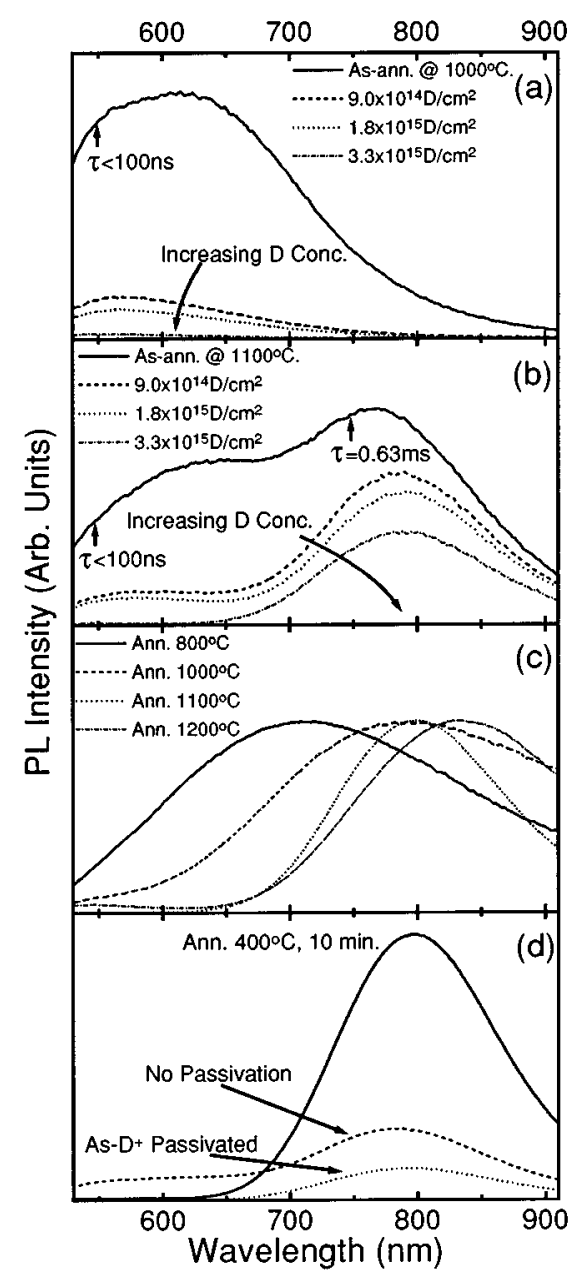

FIG. 3. Room temperature visible PL spectra and lifetime measurements of $100 \mathrm{~nm} \mathrm{SiO}{ }_{2}$ films implanted with (a) $120 \mathrm{keV} \mathrm{Xe}^{+}$to a dose of 1.3 $\times 10^{16} / \mathrm{cm}^{2}$ and annealed at $1000{ }^{\circ} \mathrm{C}$ for $10 \mathrm{~min}$ and (b) $50 \mathrm{keV} \mathrm{Si}{ }^{+}$to a dose of $5 \times 10^{16} / \mathrm{cm}^{2}$ and annealed at $1100{ }^{\circ} \mathrm{C}$ for $10 \mathrm{~min}$. Short arrows indicate the wavelengths at which lifetimes were measured. Long arrows indicate the effect of subsequent D passivation using $600 \mathrm{eV}$ D; (c) PL peak energy shift of $50 \mathrm{keV} \mathrm{Si}{ }^{+}$-implanted $\mathrm{SiO}_{2}$ after passivation. All samples were implanted with $\mathrm{Si}$ to a dose of $5 \times 10^{16} / \mathrm{cm}^{2}$, annealed in vacuum, and subsequently passivated with $3.3 \times 10^{15} / \mathrm{cm}^{2} \mathrm{D}$ to quench the defect-related PL. All spectra are normalized; (d) PL intensity increase upon postdeuteration annealing the film of (b) at $400{ }^{\circ} \mathrm{C}$ for $10 \mathrm{~min}$.

nescence can be attributed to radiative recombination of quantum-confined excitons. First, the value of the lifetime measured at $750 \mathrm{~nm}$ is consistent with theoretical predictions ${ }^{15}$ for Si nanocrystals around $2.5 \mathrm{~nm}$. In addition to a faster component limited by experimental resolution, a slower component was observed with a $1 / e$ decay time of $0.63 \mathrm{~ms}$, as indicated in Fig. 3(b).

Second, the peak energy of the "red" luminescence after deuteration "redshifts" as a function of implantation dose and annealing temperature. This is illustrated in the normalized PL spectra of Fig. 3(c) for $5 \times 10^{16} / \mathrm{cm}^{2}$ $\mathrm{Si}^{+}$-implanted samples annealed at different temperatures. All samples were deuterated with an equal dose of deuterium of $3.3 \times 10^{15} / \mathrm{cm}^{2}$. A clear shift in PL peak energy from 710 $\mathrm{nm}(1.75 \mathrm{eV})$ to $840 \mathrm{~nm}(1.48 \mathrm{eV})$ is observed between samples annealed at 800 and $1200{ }^{\circ} \mathrm{C}$. Similarly, a shift from $650 \mathrm{~nm}(1.91 \mathrm{eV})$ to $790 \mathrm{~nm}(1.57 \mathrm{eV})$ was observed between samples implanted with $2 \times 10^{16} / \mathrm{cm}^{2} \mathrm{Si}$ and 5 $\times 10^{16} / \mathrm{cm}^{2} \mathrm{Si}$, respectively, after annealing at $1000{ }^{\circ} \mathrm{C}$ and passivating with $3.3 \times 10^{15} / \mathrm{cm}^{2}$ deuterium.

Third, deuterated samples display a dramatic increase in PL intensity upon low temperature $\left(<500{ }^{\circ} \mathrm{C}\right)$ postdeuteration annealing, which increases the mobility of deuterium atoms. It appears that the implanted deuterium atoms have enough mobility at room temperature to passivate defects in the matrix but require higher atomic mobility to further passivate dangling bonds at the nanocrystal/ $/ \mathrm{SiO}_{2}$ interface. This is illustrated in Fig. 3(d) for the deuterated sample of Fig. 3(b). Upon annealing at $400{ }^{\circ} \mathrm{C}$ for $10 \mathrm{~min}$, the intensity of the "red" luminescence increases dramatically, by as much as a factor of 10 . This is consistent with the notion that passivation of dangling bonds at the nanocrystal/ $/ \mathrm{SiO}_{2}$ interface leads to an enhancement of radiative recombination. The PL intensity increases to a maximum at post-deuteration annealing temperature of $400{ }^{\circ} \mathrm{C}$ and starts to decrease at higher temperatures, presumably due to the release of deuterium from defects at the nanocrystal/ $/ \mathrm{SiO}_{2}$ interface and subsequent out diffusion from the film.

Finally, the luminescence intensity scales with the volume density of $\mathrm{Si}-\mathrm{Si}$ bonds, as revealed by XPS results. The luminescence intensity increases with increasing dose, annealing temperature, and annealing time. Increasing any one or more of these three processing parameters increases the intensity of bulk Si $2 p$ core level signal in XPS, suggesting a corresponding increase in the volume density of $\mathrm{Si}-\mathrm{Si}$ bonds. This is most likely associated with an increase in nanocrystal density, since the particles do not coarsen significantly beyond the size of about $2.5 \mathrm{~nm}$, as deduced from our limited TEM results.

The authors acknowledge M. Easterbrook and A. Rice for technical assistance. This work was supported by the U.S. Department of Energy under Grant No. DE-FG0389ER45395 and NATO Ministry for Scientific Affairs. The work at FOM was financially supported by NWO, STW, and IOP Electro-Optics.

${ }^{1}$ R. A. Soref, Proc. IEEE 81, 1687 (1993).

${ }^{2}$ L. T. Cahnam, Appl. Phys. Lett. 57, 1046 (1990).

${ }^{3}$ Y. Maeda, Phys. Rev. B 51, 1658 (1994).

${ }^{4}$ Q. Zhang, S. C. Bayliss, and D. A. Hutt, Appl. Phys. Lett. 66, 1977 (1995).

${ }^{5}$ L. E. Brus, P. F. Szajowski, W. L. Wilson, T. D. Harris, S. Schuppler, and P. H. Citrin, J. Am. Chem. Soc. 117, 2915 (1995).

${ }^{6}$ T. S. Iwayama, S. Nakao, and K. Saitoh, Appl. Phys. Lett. 65, 1814 (1994).

${ }^{7}$ P. Mutti et al., Appl. Phys. Lett. 66, 851 (1995).

${ }^{8}$ H. M. Cheong, W. Paul, S. P. Withrow, J. G. Zhu, J. D. Budai, C. W. White, and D. M. Hembree, Jr., Appl. Phys. Lett. 68, 87 (1996); J. G. Zhu, C. W. White, J. D. Budai, S. P. Withrow, and Y. Chen, J. Appl. Phys. 78, 4386 (1995).

${ }^{9}$ L. Skuja, J. Non-Cryst. Solids 179, 51 (1994).

${ }^{10}$ K. S. Seol, A. Ieki, Y. Ohki, H. Nishikawa, and M. Tachimori, J. Appl. Phys. 79, 412 (1996).

${ }^{11}$ K. S. Min, K. V. Shcheglov, C. M. Yang, H. A. Atwater, M. L. Brongersma, and A. Polman, Appl. Phys. Lett. 68, 2511 (1996).

${ }^{12}$ J. F. Ziegler, J. P. Biersack, and U. Littmark, The Stopping and Range of Ions in Solids (Pergamon, New York, 1985).

${ }^{13}$ See, for example, Z. H. Lu, M. J. Graham, D. T. Jiang, and K. H. Tan, Appl. Phys. Lett. 63, 2941 (1993).

${ }^{14}$ G. W. Arnold, J. Non-Cryst. Solids 179, 288 (1994).

${ }^{15}$ M. Hybertsen, Phys. Rev. Lett. 72, 1514 (1994). 